\title{
PERCEPTION OF PATIENTS UNDERGOING HYSTEROSALPHINGOGRAPHY (HSG) IN KANO METROPOLIS, NIGERIA
}

\author{
${ }^{1}$ Sidi, M., ${ }^{* 1} Y a '$, A. and ${ }^{2}$ Dambatta, A.H. \\ ${ }^{* 1}$ Department of Medical Radiography, Faculty of Allied Health Sciences, Bayero University, Kano \\ ${ }^{2}$ Department of Radiology, Bayero University/Aminu Kano Teaching Hospital Kano \\ *Corresponding author: ayau.radg@buk.edu.ng +2348066338046
}

\section{ABSTRACT}

Hysterosalphingography (HSG) is a special radiological procedure that is used to assess the patency and the structure of the uterus and Fallopian tubes. The main role of HSG is the study of the Fallopian tubes in infertility. Discomfort, anxiety, and pain that might arise as a result of the procedure and may vary depending on the individual's perception. The patient's perception of a procedure plays an important role in its acceptance. The study aims at evaluating the perception of patients undergoing HSG examination in Kano metropolis. The study design was prospective and cross-sectional conducted in the Radiology Departments of four hospitals in the Kano metropolis from December 2018 to March 2019. A non-probability sampling method was employed in the study. An ethical clearance to conduct the study was obtained from the Human Research and Ethics Committee of the Kano State Ministry of Health. A structured questionnaire was used as an instrument for data collection. The questionnaire was validated by experienced colleagues and using pilot study the reliability of the measuring tool was tested and the Chronbach reliability coefficient was found to be 0.79 . Two hundred and fifty six questionnaires were administered to the selected respondents. An informed consent was obtained from all the selected respondents. The obtained data were analyzed using SPSS version 21.0. Out of the 256 (100\%) administered questionnaires, 237 (92.6\%) were returned, and 226 (88.3\%) were properly filled. In 189 (83.63\%) respondents, infertility was found to be the indication for the procedure. 82 (36.3\%) of the respondents believed the procedure was for diagnostic purpose, 78 (34.5\%) for therapeutic and $28.3 \%$ for diagnostic and therapeutic. Patients undergoing HSG in Kano metropolis had a negative perception towards the procedure.

Keywords: Perception, Hysterosalphingography, Kano metropolis

\section{INTRODUCTION}

Hysterosalphingography (HSG) is a special radiological procedure that is used to assess the patency and the structure of the uterus and Fallopian tubes (Danfulani et al., 2014). It visualizes the delineation of the uterine cavity and evaluates tubal patency radio-graphically by trans-cervical injection of contrast medium. The main role of HSG is the study of the Fallopian tubes in infertility. However, it can be used in other cases: pelvic pain, congenital or anatomic abnormalities, anomalies of the menstrual cycle, the study of abnormal menses (Chalazonitis et al., 2009), women with recurrent spontaneous abortions and the postoperative evaluation of women who have had surgical tubal ligation or reversal of the ligation (Simpson et al., 2006). Another recent indication for HSG is the need to prove tubaric occlusion after the insertion of trans-cervical sterilization micro-inserts (Lazarus et al., 2012). It is one of the most common special radiological investigations in Nigeria (Nwobi et al., 2014, Ugwu et al., 2009).

Hysterosalphingography is an invasive procedure, generally regarded as uncomfortable and painful (Szymusik et al., 2015, Costello et al., 2002). Contraindications for the procedure include possible pregnancy, which can be avoided performing the HSG between the $5^{\text {th }}$ to $12^{\text {th }}$ days of the menstrual cycle. Other main contraindications are iodine allergy and active pelvic inflammation (Chalazonitis et al., 2009 \& Simpson et al., 2006). Recent dilatation and curettage, severe cardiac or renal disease, uterine malignancy, endometrial carcinomas are also considered to be contraindications (Moi et al., 2017). Some complications can occur with HSG; the two most common of which are bleeding and infection. The patient may experience light spotting after the procedure, usually lasting less than 24 hours. 
BAJOPAS Volume 12 Number 2, December, 2019

The exclusive use of sterile instruments minimizes the risk of infection. However, some patients may experience severe pain, leading to premature termination of the procedure or, rarely, a vaso-vagal reaction. There is the potential for a reaction to the contrast material; however, such a reaction is very uncommon with the use of currently available low-osmolar nonionic contrast agents. There is also the potential for a systemic reaction to the contrast material if vascular intravasation occurs (William et al., 2006). Despite continuous progress in diagnostic methods and the challenges associated with HSG, it is difficult to be replaced because of its reliability, simplicity, availability, and cost-efficiency (Szymusik et al., 2015),

Discomfort, anxiety, and pain that might arise as a result of the procedure may vary depending on the individual's perception. Perception deals with the human senses that generate signals from the environment through sight, hearing, touch, smell and taste. Szymusik et al., (2015) found an abnormal result of HSG to be the main factor that increased pain during contrast instillation and spillage. Aubrey et al., (2014) demonstrates that most women experience pain during a HSG procedure, most frequently described as cramping. Therefore, suggest continued basic scientific research as necessary to identify predictors of HSG-associated pain and measures that are effective in alleviating procedure-related discomfort. The patient's perception of a procedure plays an important role in its acceptance (Ugwu et al., 2009).

Despite being one of the most common special radiological procedures, little information is available regarding patient perception of the procedure (Aubrey et al., 2014). There is a paucity of data concerning perception of patients undergoing HSG examination in Kano metropolis. The findings of the study will serve as a guide to the radiologist/radiographers with a better understanding of patients' perception, HSG patient will be better counseled about the procedure in order to alleviate or reduced any negative expectations towards HSG examination. It will also increase patient cooperation and understanding prior, during and after the procedure. The study aims at evaluating the perception of patients undergoing HSG examination in Kano metropolis.

\section{MATERIALS AND METHODS}

The study design was prospective and crosssectional conducted in the Radiology Departments of four hospitals in the Kano metropolis from December 2018 to March 2019. A non-probability sampling method was employed in the study. An ethical clearance to conduct the study was obtained from the Human Research and Ethics Committee of the Kano State Ministry of Health (MOH/OFF/797/T.I/1153). A structured questionnaire was used as an instrument for data collection. The questionnaire was validated by experienced colleagues and using pilot study the reliability of the measuring tool was tested and the Chronbach reliability coefficient was found to be 0.79 . The questionnaire consists of two sections; section $A$, was the demographic information of the respondents, while section $B$, explored the perception of the respondents on HSG. Two hundred and fifty six questionnaires were administered to the selected respondents. An informed consent was obtained from all the selected respondents. The obtained data were analyzed using SPSS version 21.0.

\section{RESULTS}

Out of the $256 \quad(100 \%)$ administered questionnaires, 237 (92.6\%) were returned, and $226(88.3 \%)$ were properly filled.

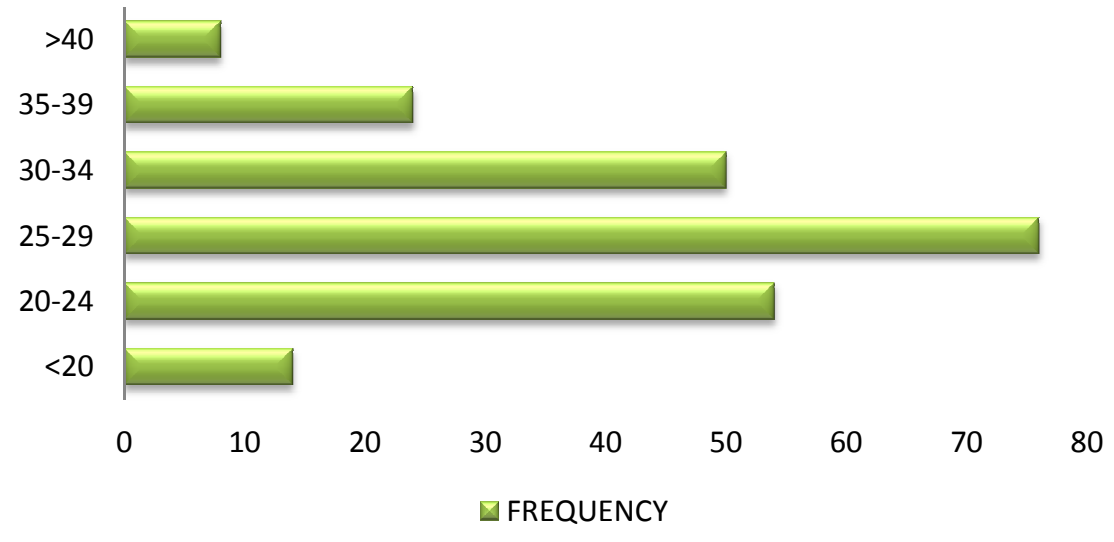

Figure 1: Age distribution of the respondents, 76(33.6\%) of the respondents are within the age bracket of 25$29 y e a r s$ followed by $20-24 y r s 54(23.9 \%)$. 40years and above were the least among our respondents $8(3.5 \%)$ then $14(6.2 \%)$ having the age of less than 20 years. 


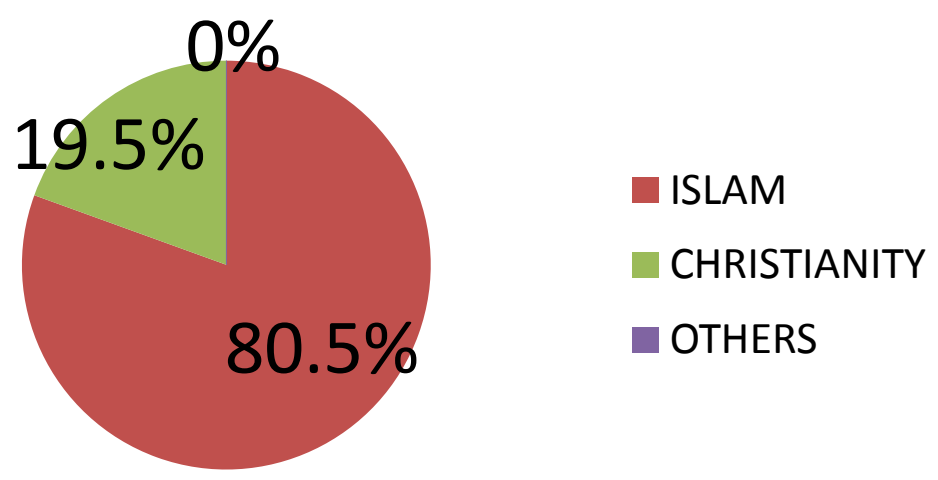

Figure 2: Distribution of respondents based on religion, 182(80.5\%) of the respondents are Muslims and $44(19.5 \%)$ were Christians.

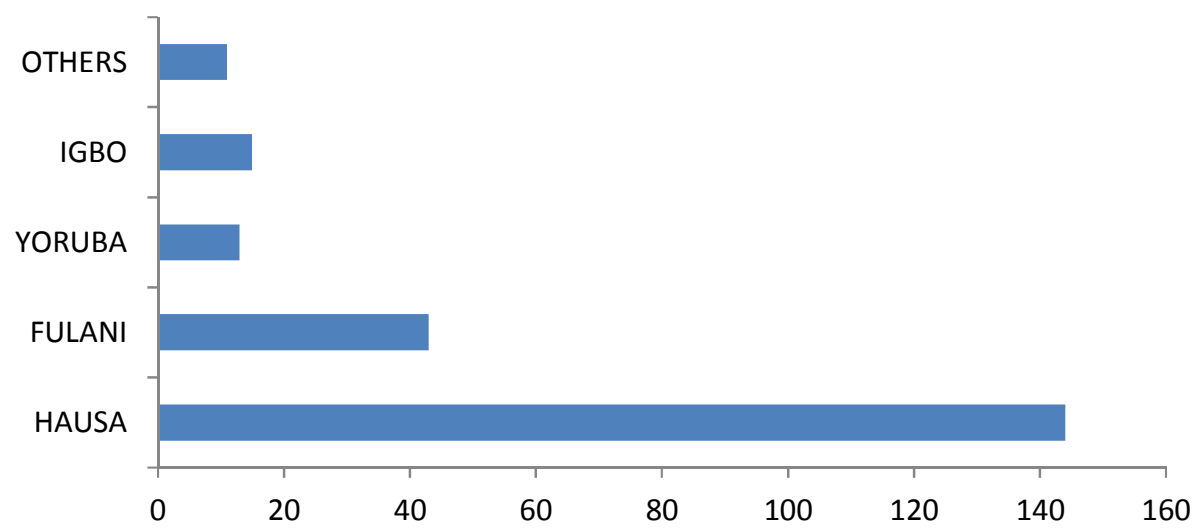

Figure 3: Shows tribe of the respondents, Hausa were the major tribe of the respondents 144(63.4\%), followed by 43(19.0) Fulani, 15(6.6\%) Igbos, 13(5.8\%) Yoruba, and 11(4.9) other tribes

\section{- PRIMARY $\square$ SECONDARY}

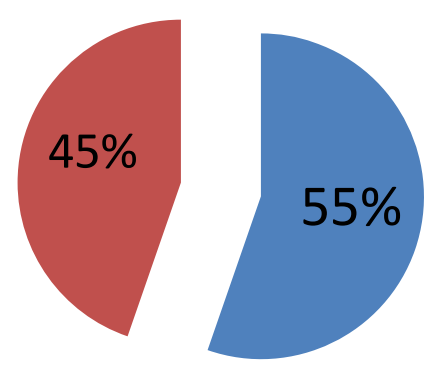

Figure 4: Shows respondent's infertility status, 125(55\%) of the respondents had primary infertility, $101(45 \%)$ secondary infertility. 


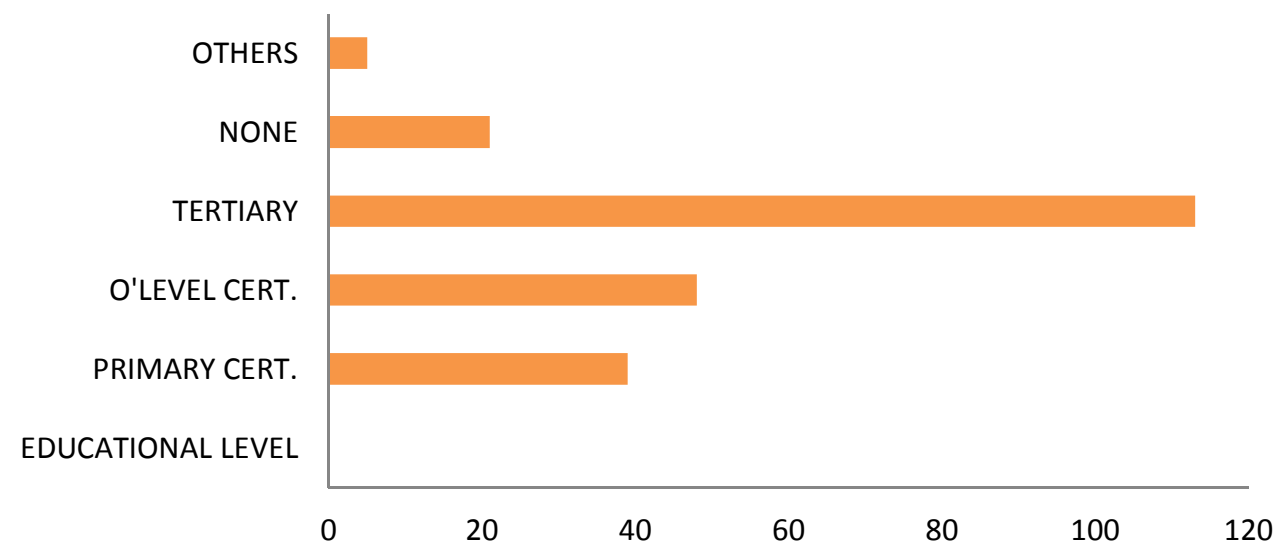

Figure 5: Educational qualification of the respondents, 113(50\%) had attended tertiary institution, $48(21.1 \%)$ had O level certificate, $39(17.3 \%)$ had primary leaving certificate, while $21(9.3 \%)$ had no any educational certificate and $5(2.2 \%)$ had other certificates

Table 1: Respondents response to questions regarding their perception about Hysterosalphingography examination

\begin{tabular}{lll}
\hline Questions & Response & Frequency (\%) \\
\hline $\begin{array}{l}\text { Q6. Why will you undergo this } \\
\text { procedure? }\end{array}$ & Infertility & $189(83.63 \%)$ \\
& Fibroid & $20(8.85 \%)$ \\
& Post surgical follow-up & $12(5.31 \%)$ \\
Q7. What benefit do you expect & Others & $00(0 \%)$ \\
from the procedure? & Missing data & $05(2.21 \%)$ \\
& Diagnostics & $82(36.3 \%)$ \\
Therapeutic & $78(34.5 \%)$ \\
Q8. Have you heard about this & All of the above & $64(28.3 \%)$ \\
examination before? & Missing data & $02(0.9 \%)$ \\
& Yes & $92(40.71 \%)$ \\
Q9. Does someone explain the & No & $133(58.85 \%)$ \\
procedure to you? & Missing data & $01(0.44 \%)$ \\
& Yes & $89(39.4 \%)$ \\
Q10. Who do you think will perform & No & $136(60.2 \%)$ \\
the procedure for you? & Missing data & $1(0.4 \%)$ \\
& Male & $28(12.4 \%)$ \\
Q11. Are you afraid about the & Female & $114(50.4 \%)$ \\
examination? & Don't care & $82(36.3 \%)$ \\
Q12. Are you expecting discomforts & Missing data & $02(0.9 \%)$ \\
from the procedure? & Yes & $131(57.9 \%)$ \\
& No & $93(41.2 \%)$ \\
& Missing data & $02(0.9 \%)$ \\
& Yes & $122(54 \%)$ \\
& Missing data & $95(42 \%)$ \\
& & $09(4 \%)$
\end{tabular}


Table 1: continue

Q13. Are you expecting pain from the procedure? If yes answer question 14 but if no proceed

Q14. What is the severity of the pain are you expecting?

Q15. Are you expecting bleeding from the procedure? If yes answer question 16 but if no proceed to question 17

Q16. What is the severity of the bleeding are you expecting?

Q17. Do you expect to be traumatized from the procedure?

Q18. Do you feel the procedure is expensive?

$\begin{array}{ll}\text { Yes } & 154(68.1 \%) \\ \text { No } & 70(31 \%) \\ \text { Missing data } & 02(0.9 \%) \\ & \\ \text { Mild } & 49(21.7 \%) \\ \text { Moderate } & 64(28.3 \%) \\ \text { Severe } & 39(17.3 \%) \\ \text { Missing data } & 74(32.7 \%) \\ & \\ \text { Yes } & 74(32.7 \%) \\ \text { INo } & 148(65.5 \%) \\ \text { Missing data } & 04(1.8 \%)\end{array}$

Mild

Moderate

Severe

Missing data

$44(19.5 \%)$

$20(8.8 \%)$

$09(4 \%)$

$153(67.7 \%)$

Yes

$59(26.1 \%)$

No

$164(72.6 \%)$

Missing data

$03(1.3 \%)$

$\begin{array}{ll}\text { Yes } & 78(34.5 \%) \\ \text { No } & 84(37.2 \%) \\ \text { Don't care } & 63(27.9 \%) \\ \text { Missing data } & 01(0.4 \%)\end{array}$

\section{DISCUSSION}

The findings of the current study show that $83.6 \%$ of the respondents had infertility as an indication for undergoing the procedure. The findings are similar to the findings of the studies reported by Danfulani et al., (2014) and Abubakar et al., (2016). The agreement between the findings of the current study and previous published articles might be because the studies were conducted in the same region of the country. The current study shows that $36.3 \%$ of the respondents believed the procedure was for diagnostic, $34.5 \%$ believed was for therapeutic purpose and $28.3 \%$ believed was for both diagnostic and therapeutic purposes. This is contrary to the findings of the study conducted by Tyrrell at al., (1993) in United Kingdom showed that $95 \%$ of the respondents knew why the examination was performed. However, a study conducted by Hussain et al., (2007) reported that with the Explanation of the procedure to the patients will certainly influence their perception, therefore detail explanation of the procedure, including how the procedure is performed, benefits and possible complication should be well explained to the patients. application of hydrostatic pressure during HSG technique, there was a $24 \%$ rate of successful conception in women within 3-6 months after the procedure. The majority of the respondents had a wrong perception of the main purpose of performing the HSG procedure, and need to be educated before the procedure that the main purpose is for diagnostic not therapeutic. The findings of the current study show that $58.9 \%$ of respondents never had of the procedure before, and since the majority had infertility as an indication of the procedure, might be linked to the wrong perception of the main purpose of the procedure.

The findings of the current study also show that the procedure was not explained to the $60.2 \%$ of the respondents. This is in disagreement with the study conducted by Tyrrell at al., (1993) which showed $53 \%$ of the respondents had received an explanation of the procedure prior to their arrival in the X-ray Department. According to our study, $50.4 \%$ of the respondents expected females to perform the procedures; however, through observation and experience this is not obtainable in our locality. The team usually consists of both males and females. The current study shows that $57.9 \%$ of 
BAJOPAS Volume 12 Number 2, December, 2019 the respondents were afraid of undergoing the procedure; this might be linked to the lack of detail explanation of the procedures or false information received from other people. Giving the detail explanation of the procedure to the patient and proper counseling will certainly change this perception. The findings of the current study show that $54 \%$ of the respondents were expecting discomfort during the procedure, whereas $68.1 \%$ of the respondents were expecting pains during the procedure. Expecting a pain usually affects the level of cooperation of the patient before and during the procedure, which will affect the timely performance of the procedure. Explaining to the patients that pain relievers and antispasmotic will be administered to reduced or prevent the perceived pain may calm down the anxiety associated with pain. Furthermore, the findings of the study show that $21.7 \%$ of the respondents expected mild pain, $28.3 \%$ moderate pain and $17.3 \%$ expected severe pain.

The severity of the expected pain may determines the level of anxiety developed by a patient undergoing procedure which may in turn affects the level of cooperation received from the patient during the procedure. Our findings also shows only $32.7 \%$ of the respondents expected bleed from the procedure, $19.5 \%$ of the respondents expected mild bleed, $8.8 \%$ moderate bleed and $4 \%$ expected severe bleed.

\section{REFERENCES}

Abubakar A., Ali Y.M., Nwobi I.C., Nkubli B.F., Miftaudeen M.N., Njiti M.M., Luntsi G., Moi A.S., Kurama M.B., Gunda N.M. (2016). Common hysterosalpingography protocols and findings among infertile women in a tertiary healthcare institution in northeast, Nigeria, Journal of Dental and Medical Sciences, 15(7): 124-127

Aubrey P., Alexander M.Q., Karl R.H., Blake P., Heather B., and La Tasha B.C. (2014). Predictors of pain associated with hysterosalpingography (HSG): A prospective cohort study, Austin Journal of Women's Health; 1(2): 1-4

Chalazonitis A., Tzovara I., Laspas F., Porfyridis P., and Ptohis N.T.G. (2009). Hysterosalpingography: Technique and applications. Curr Probl Diagn Radiol, 38 (5):199-205.

Costello M.F., Stephen H., Stephen S., Najwa Saif, M.D., Michael B., and Abie E. (2002). Transcervical intrauterine topical local anesthetic at hysterosalpingography: a prospective, randomized, double-blind, placebo-
Procedure associated with bleeding may cause fear and anxiety more especially if the associated bleed is severe.

We also found that $72.6 \%$ of the respondents were not expecting trauma from the procedure, however, $26.1 \%$ of the respondents were expecting trauma from the procedure. Procedures associated with trauma as a complication causes fear and anxiety among patients which will certainly affect the success of the performance of the procedure. Furthermore, the findings of the current study show that $34.5 \%$ of the respondents indicated high cost of the performance of the procedure, $37.2 \%$ were satisfied with the cost. The cost of the performance of a procedure is another important factor to consider in patient's perception more especially in a low socioeconomic society as in the case of the current study. The findings of the current are contrary to the findings of the study conducted by Ugwu at al., (2009) that reported good perception among patients undergoing special radiological investigations.

\section{CONCLUSION}

Patients undergoing hysterosalphingography (HSG) in Kano metropolis had a negative perception towards the procedure. A proper counseling and awareness need to be given to the patients undergoing the procedure.

controlled trial, American Society for Reproductive Medicine; 78 (5): 11161122

Danfulani M, Mohammed M.S., Ahmed S.S., Haruna YG. (2014). Hysterosalphingographic findings in women with infertility in Sokoto North Western Nigeria. African Journal of Medical and Health Sciences, 13 (1): 1923.

Eduwem D. U., Akintomide A. O., Bassey D. E., and Ekott M. I. (2016). Hysterosalpingographic patterns and relevance in the management of infertility in a Nigerian tertiary health Institution. Asian Journal of Medical Sciences; 7 (5): 70-74

Hussain M., Al Damegh S., and Tabish A. (2007). Therapeutic efficacy of hysterosalpingography with special reference to application of hydrostatic pressure during the procedure. International Journal of Health Science; 1 (2): 223-227. 
BAJOPAS Volume 12 Number 2, December, 2019

Lazarus E. Ana P. L., Susan C., and Rebecca H. A. (2012). Necessity of Hysterosalpingography after Essure Micro insert Placement for Contraception. American Journal of Roengenology, 198 (6): 1460-1463.

Moi A.S., Etim U.F., Obotiba A.D., Abubakar G.M., Luntsi G., Nkubli B.F., Nwobi I.C., and Aniekop U.P. (2017). Radiographic findings in Hysterosalpingography (HSG) of women attending infertility clinic at University of Uyo Teaching Hospital, Akwa-Ibom state, Scholarly Journal of Medicine; 5(2): 21-25

Nwobi I. C., Luntsi G., Ahmadu M. S., Nkubli F. B., Kawu H. D., Dauda F., Moi A. S.

Abubakar G. M., \& Tahir M. B., (2014). The Assessment of Patients' Perception and Satisfaction of Radiology Waiting Time in University of Maiduguri Teaching Hospital. Kanem Journal of Medical Sciences; 8 (1): 19-26

Omolola M.A., \& Babatunde B.O. (2014). Do Abnormal Findings on Hystero-
Salphingographic Examination Correlate with Intensity of Procedure Associated Pain?. African Journal Reproductive Health; 18 (2): 147-151.

William L.S., Jr M.D., Laura G.B., Jolinda M.M.D. (2006). Hysterosalpingography: A Reemerging Study. RadioGraphic, 26 (2): 419-31.

Szymusik I., Barbara G., Piotr M., Bartosz K., and Miroslaw W. (2015). Factors Influencing the Severity of Pain During Hysterosalpingography. International Journal of Gynecology and Obstetrics; 129 (2): 118-122

Tyrrell P.N.M., Mchugo J. M., Hale M. (1993). Patients' perception of the hysterosalpingogram: The initial stages of the audit cycle. The British Journal of Radiology; 66 (782): 103-107

Ugwu A.C., Samuel L. S., Felix E., (2009). Patients' Perception of Care During Special Radiological Examinations. African Journal of Primary Health Care \& Family Medicine; 1(1): 100-102 